\title{
A scoping review on disparities in exposure to advertising for e-cigarettes and heated tobacco products and implications for advancing a health equity research agenda
}

\author{
Graziele Grilo ${ }^{*}$, Elizabeth Crespi and Joanna E. Cohen
}

\begin{abstract}
Background: Disparities in exposure to and density of tobacco advertising are well established; however, it is still unclear how e-cigarette and heated tobacco product (HTP) advertising vary by age, education, sex, gender identity, race/ethnicity, sexual orientation, socioeconomic status (SES), and/or urban/rural area. Through a scoping review, we sought to identify potential disparities in exposure to e-cigarette and HTP advertising and promotion across populations.
\end{abstract}

Methods: In January 2020, a systematic literature search was conducted in five databases: PubMed, Scopus, Embase, Web of Science, and the Cochrane Library. The search was updated in October 2020. Articles reporting on exposure to e-cigarette and/or HTP advertising and promotion across age, education, sex, gender identity, race/ethnicity, sexual orientation, SES, and/or urban/rural areas were included for full-text review $(n=25)$. Of those, 15 were deemed relevant for data extraction.

Results: The majority of the studies were from the U.S. $(n=12)$ and cross-sectional $(n=14)$. Studies were published between 2014 and 2020 and focused on determining causal relationships that underlie disparities; only one study assessed HTP advertising and promotion. Exposure to e-cigarette and HTP advertising was assessed at the individuallevel (e.g., recall seeing ads on television) and at the neighborhood-level (e.g., ad density at the point-of-sale). Studies addressed differences across age $(n=6)$, education $(n=2)$, sex $(n=6)$, gender identity and sexual orientation $(n=3)$, race/ethnicity $(n=11)$, SES $(n=5)$, and urban/rural $(n=2)$. The following populations were more likely to be exposed to e-cigarette advertising: youth, those with more than a high school diploma, males, sexual and gender minorities, Whites, and urban residents. At the neighborhood-level, e-cigarette advertisements were more prevalent in nonWhite neighborhoods.

Conclusions: Exposure to e-cigarette/HTP advertising varies based on sociodemographic characteristics, although the literature is limited especially regarding HTPs. Higher exposure among youth might increase tobacco-related disparities since it can lead to nicotine/tobacco use. Research should incorporate and apply a health equity lens from its inception to obtain data to inform the elimination of those disparities.

\footnotetext{
*Correspondence: ggrilo@jhu.edu

Institute for Global Tobacco Control, Department of Health, Behavior and Society, Johns Hopkins Bloomberg School of Public Health, 2213 McElderry Street, Fourth Floor, Baltimore, MD 21205, USA
}

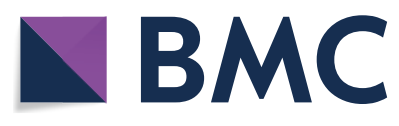

(c) The Author(s) 2021. Open Access This article is licensed under a Creative Commons Attribution 4.0 International License, which permits use, sharing, adaptation, distribution and reproduction in any medium or format, as long as you give appropriate credit to the original author(s) and the source, provide a link to the Creative Commons licence, and indicate if changes were made. The images or other third party material in this article are included in the article's Creative Commons licence, unless indicated otherwise in a credit line to the material. If material is not included in the article's Creative Commons licence and your intended use is not permitted by statutory regulation or exceeds the permitted use, you will need to obtain permission directly from the copyright holder. To view a copy of this licence, visit http://creativecommons.org/licenses/by/4.0/. The Creative Commons Public Domain Dedication waiver (http://creativeco mmons.org/publicdomain/zero/1.0/) applies to the data made available in this article, unless otherwise stated in a credit line to the data. 
Keywords: E-cigarette, Heated tobacco products, Tobacco advertising and promotion, Health equity, Tobaccorelated disparities

\section{Introduction}

Factors such as housing, discrimination, employment, and education have been shown to impact individual and population-level health, resulting in systematic and avoidable health disparities among certain populations [1-3]. Tobacco use, for example, disproportionately affects those living in poverty, suffering from mental illness, and with lower educational attainment [4]. In fact, smoking contributes substantially to health disparities; low socioeconomic status (SES) populations have higher smoking rates $[5,6]$ and greater smoking-related mortality [7]. Differences in mortality rates between those of high- and low-SES have been linked largely to smoking [8]. Previous research has shown that the tobacco industry has targeted populations that have been excluded or marginalized; a systematic review of the literature found elevated tobacco advertising in lower income neighborhoods [9]. Additionally, menthol advertising is more prevalent in low-SES, urban, and disproportionately Black neighborhoods $[9,10]$. Laws et al. found a higher proportion of businesses with storefront tobacco advertising in predominantly Black or Latino, low-SES neighborhoods [10]. Evidence suggests the tobacco industry creates product brand identities targeting certain populations [11]. This purposive targeting is concerning, as evidence has shown that tobacco advertising can reinforce beliefs that tobacco use is normal $[11,12]$. Moreover, several studies have linked advertising exposure to smoking initiation, susceptibility to smoking, and smoking behaviors, leading to a 2012 declaration by the U.S. Surgeon General that exposure to tobacco advertising causes smoking initiation [13].

The elimination of these disparities by addressing the social determinants of health is necessary in achieving health equity, in which "everyone has a fair and just opportunity to be as healthy as possible" [14]. However, there is a need to better understand the pathways through which social determinants influence health and the effectiveness of interventions that address these determinants in improving health for all populations [3]. Research can support this goal by documenting, understanding, and addressing disparities. Thomas et al. provide a framework for advancing health equity through research [15]. The Health Equity Action Research Trajectory (HEART) paradigm categorizes studies into four research generations: (1) document existing disparities; (2) determine causal relationships that underlie disparities; (3) identify solutions for eliminating disparities using transdisciplinary research, community engagement, and translational research; and (4) take action to eliminate disparities by using public health critical race praxis as a conceptual framework, addressing structural determinants of health through multilevel interventions, using comprehensive evaluation, and engaging in self-reflection as researchers [15]. The framework is also useful for evaluating gaps in the current literature because it identifies necessary steps for advancing a health equity research agenda by categorizing research in each generation [15].

The recent emergence of e-cigarettes and heated tobacco products (HTPs) has raised concerns about how they might increase/decrease tobacco-related disparities. Similar concerns have also been raised regarding advertising exposure, including that these products may renormalize cigarette smoking [16, 17]. E-cigarettes are electronic devices that heat a liquid to produce an aerosol for inhalation, which often contains nicotine and flavorings, but can also contain THC, CBD, vitamins, and other additives. Though the industry has marketed e-cigarettes as smoking cessation and harm reduction tools [18], research on their effectiveness for smoking cessation is mixed $[19,20]$.

HTPs produce an aerosol by electronically heating tobacco [21]. HTPs have been marketed as less harmful alternatives to combustible tobacco products [22], though these devices still produce harmful emissions [23] and further research is needed to understand their health effects [24].

In 2018, the tobacco industry spent $\$ 110$ million on e-cigarette advertising in the U.S. alone [25]. This same year, the U.S. Surgeon General declared that e-cigarette use among youth was an epidemic due to its rapid increase among middle and high-school students [26]. Evidence suggests that e-cigarette advertising influences perceptions of and interest in e-cigarettes among adolescents [27]. A study found that e-cigarette advertising in the U.S contained youth-appealing features [28]. Research has also shown that e-cigarette use may result in transitions to cigarette smoking [29], leading to further concerns about how these devices may affect existing disparities in health outcomes related to tobacco. Current research in this regard has not been fully explored; a systematic review found different patterns for e-cigarette awareness, ever use, and current use based on sociodemographic characteristics, highlighting the need to ensure the potential benefits and risks of e-cigarettes do not increase current health disparities [30]. Two other 
systematic reviews examined the potential equity impact of non-combustible nicotine products, including e-cigarettes, for cigarette smoking cessation/reduction [31] and smokers' engagement with these products [32] among smokers from different SES. These studies found little evidence of the impact of e-cigarettes on cigarette smoking disparities [31] and a lack of studies on higher-SES groups [32].

It remains unknown how these devices are currently being advertised to various populations, if exposure level varies across populations, and how this might impact tobacco-related disparities. This paper aims to fill this gap by answering the following questions: (1) According to the current literature, how does e-cigarette/HTP advertisement exposure differ across race/ethnicity, age, education, sex, gender identity, sexual orientation, SES, and/or urban/rural areas? (2) In which generations of the HEART framework can the available literature be categorized? Understanding the disparities that exist in e-cigarette/HTP advertising and gaps in the literature may guide future research and allow for more effective action on eliminating tobacco-related disparities and advancing health equity.

\section{Methods}

In order to map the existing literature focusing on advertisement exposure across different sociodemographic characteristics, we conducted a scoping review using the steps proposed by the Arksey and O'Malley framework [33]. After 1) identifying our research questions, we 2) identified the relevant studies; 3 ) applied inclusion/exclusion criteria; 4) extracted the data; and, 5) collated, summarized, and reported the results. This analysis is part of a larger study in which the final step, 6) a consultation with experts, was also conducted; however, we do not report the results here because the consultation focused on research priorities related to e-cigarettes, HTPs, and tobacco-related disparities in relation to prevalence, susceptibility, cessation, access, and, advertising [34]. For this study, we focus on the results related to advertising.

\section{Identifying relevant studies}

The initial search was conducted on January 14, 2020 in five electronic databases (PubMed, Scopus, Embase, Web of Science, and the Cochrane Library), which were determined in consultation with a university informationist who also supported the construction of the search strategy (Table 1). We updated our search on October 19, 2020 using the same strategy and databases. Results were uploaded to Covidence, which removed duplicates automatically. In addition, one study was recommended by a convening participant.
Table 1 Search terms

\begin{tabular}{ll}
\hline$\# 1 \quad$ & Electronic Nicotine Delivery Systems[mesh] OR \\
& Vaping[mesh] OR Electronic Cigarette*[tw] OR \\
& E-Cigarette*[tw] OR E-Cig*[tw] OR Vape[tw] \\
& OR vaping[tw] OR vaper*[tw] OR JUUL[tw] OR \\
& IQOS[tw] OR heat-not-burn[tw] OR heated \\
& tobacco products[tw] OR JUULing[tw] \\
& ethnic groups[mesh] OR Socioeconomic \\
& Factors[mesh] OR Social Class[mesh] OR Age \\
& Factors[mesh] OR Sex Factors[mesh] OR Race \\
& Factors[mesh] OR Educational Status[mesh] \\
& OR health equity[mesh] OR health status \\
& disparities[mesh] OR Socioeconomic Factor*[tw] \\
& OR Inequalit*[tw] OR Sex Factor*[tw] OR \\
& Sexualit*[tw] OR Race Factor*[tw] OR Age \\
& Factor*[tw] OR sociodemographic*[tw] OR \\
& Socioeconomic Status[tw] OR Social Classes[tw] \\
& OR health equities[tw] OR Race[tw] OR \\
& Adolescen*[tw] OR Youth*[tw] OR Teen*[tw] \\
& $\# 1$ AND \#2
\end{tabular}

\section{Applying inclusion/exclusion criteria}

To meet our inclusion criteria, studies had to be 1) related to e-cigarettes and/or HTPs; and, 2) related to health equity and/or disparities. For the purposes of this paper, we also excluded studies that did not report on e-cigarette/HTP advertising. During this step, studies were also classified based on three priorities: high - clear discussion of the implications of e-cigarettes/HTPs in relation to health equity/disparities; mid - no discussion of implications, but more than just presenting descriptive information about advertising exposure by different populations OR studies that present unique data or perspective on the issue; and, low - only descriptive information on e-cigarette/HTP advertising exposure by different sociodemographic characteristics. Titles and abstracts were double-coded by independent researchers (GG, EC, AA). Disagreements related to inclusion/exclusion and/ or priority setting were resolved by consensus; a fourth researcher (JEC) made the final decision when consensus was not reached.

\section{Extracting data}

Only high and mid priority studies were eligible for full text review due to time constraints. Two researchers (GG and EC) reviewed an initial set of studies to refine data extraction procedures. Remaining studies were individually reviewed; however, excluded studies were reviewed for agreement. The following information was extracted using Microsoft Excel: a) citation; b) objective; c) study design; d) study population; e) key results and conclusion; f) policy/research implications; g) main theme; h) product type (e-cigarettes and/or HTPs); i) funding; j) research generation; $\mathrm{k}$ ) notes. 


\section{Collating, summarizing, and reporting the results}

Both researchers (GG and EC) reviewed the extracted information and categorized the studies based on the HEART paradigm. Since we were interested in assessing differences by sociodemographic characteristics, key results and conclusions were then summarized by age, education, sex, gender identity, sexual orientation, race/ ethnicity, SES, and urban/rural. Results are presented by subpopulation.

\section{Results}

\section{Results of the search}

A total of 15 studies were identified. Figure 1 illustrates the study selection process.

\section{Characteristics of included studies}

Of the 15 included studies, 12 were from the U.S. (six were nationally representative, but one only in the contiguous U.S.); one was from the U.S. and Canada; one from Guatemala; and, one did not have a specific location (i.e., the Internet). Fourteen studies were cross-sectional, and one was longitudinal. All studies were categorized as in the second generation of the HEART paradigm (determining causal relationships that underlie disparities) [15].
Exposure to e-cigarette advertising and promotion by sociodemographic characteristic was measured at the individual level, with some studies also assessing different channels of exposure, and at the neighborhood level, focusing on different points-of-sale (POS). One study focused on the content of e-cigarette advertising in magazines and another one on Twitter. Only one study assessed HTP marketing; this study observed product placement and advertising at POS in Guatemala [35]. Table 2 provides more information about the studies in the sample.

\section{Age}

Six studies reported on advertising exposure by age. Despite different study populations and locations, findings predominantly showed that adolescents and young adults are more likely to be exposed to e-cigarette and HTP advertising than adults aged 26 years and older. One U.S.-nationally representative study found higher exposure to e-cigarette advertising through TV and digital sources for adolescents between the ages of 13-17 years compared to adults over 26years old [39]. Those over 26 years old were exposed more to e-cigarette advertising through POS, radio, and print media [39] compared to the adolescents. Another nationally representative

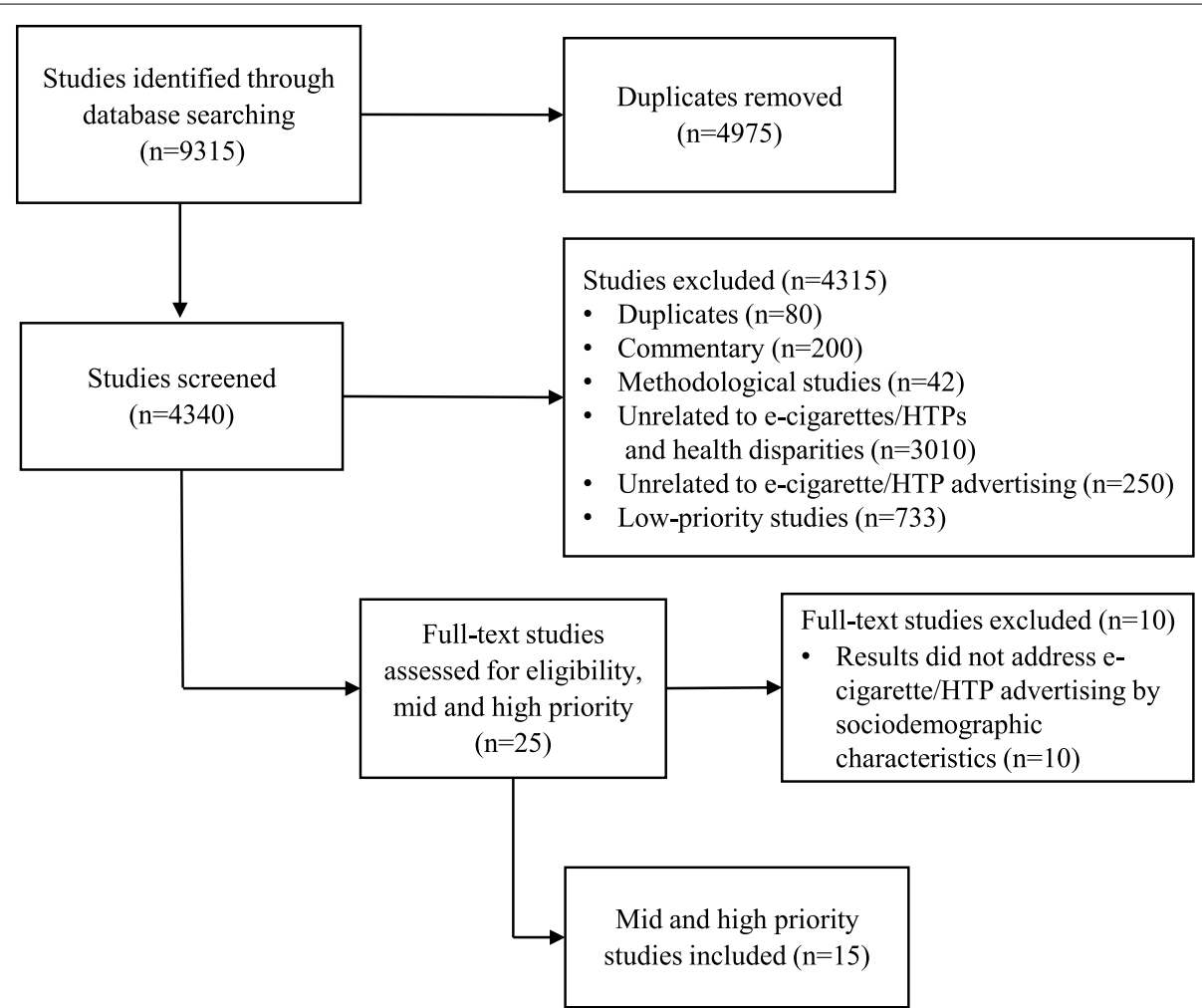

Fig. 1 Flowchart of included studies 


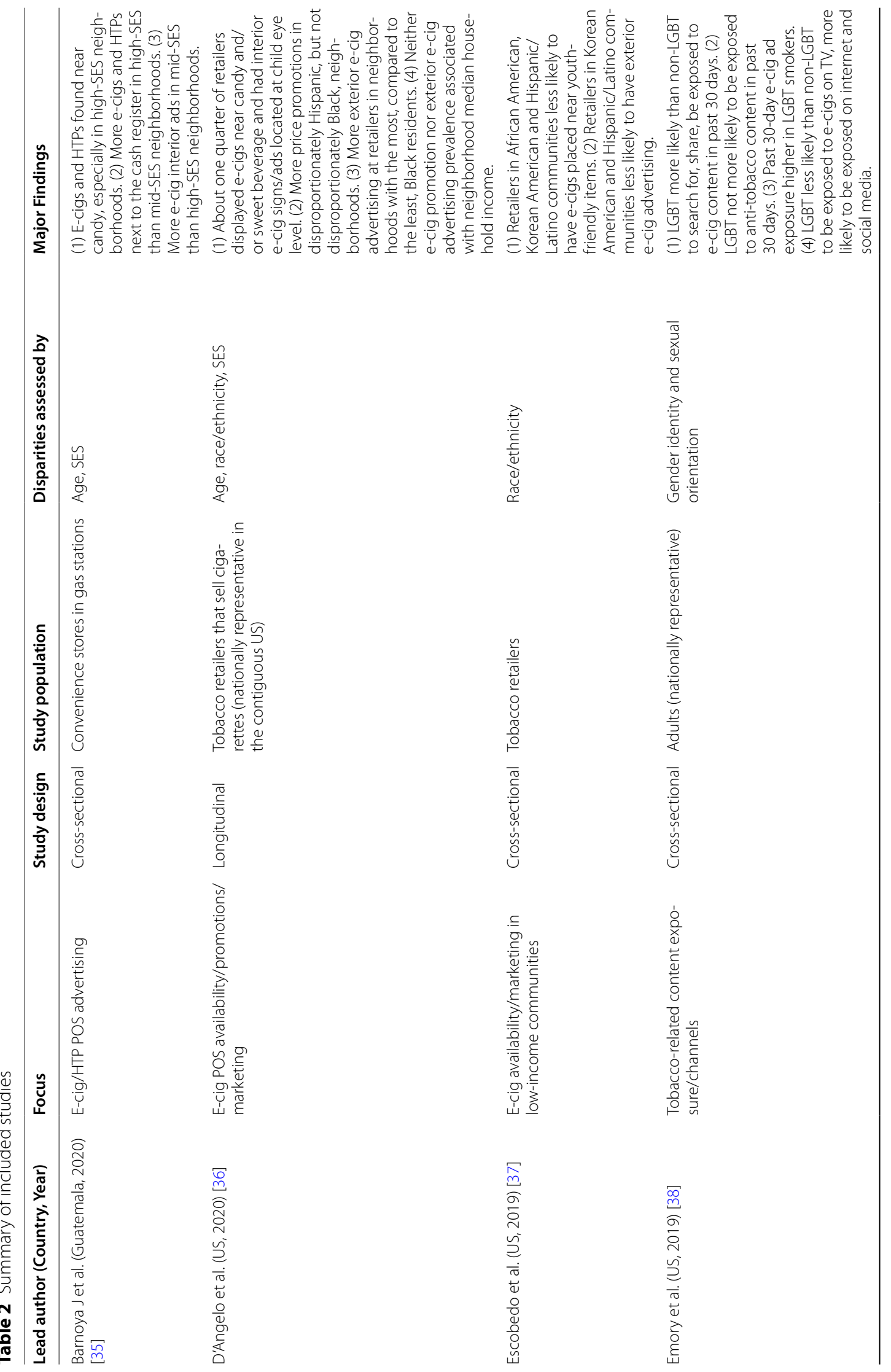




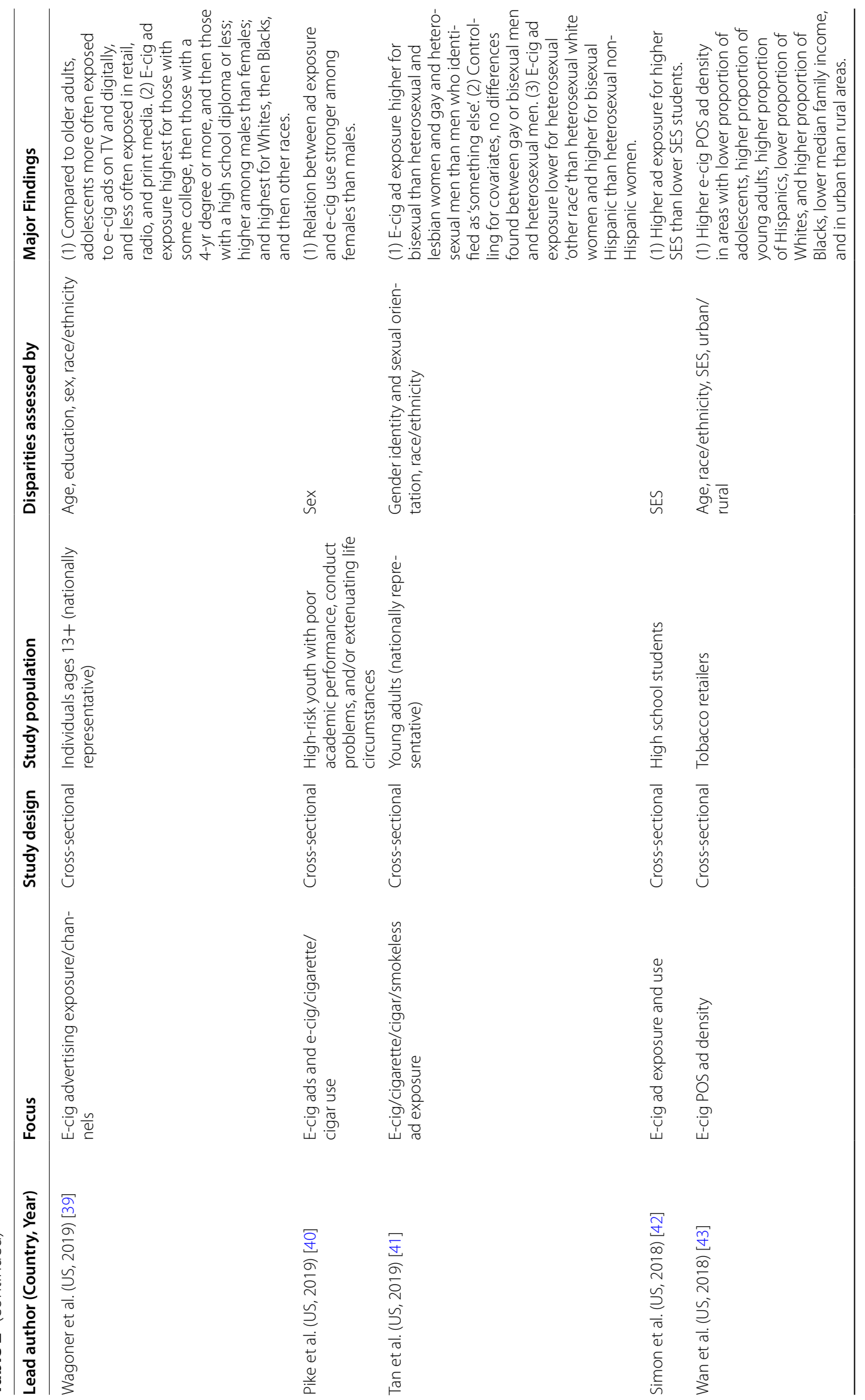




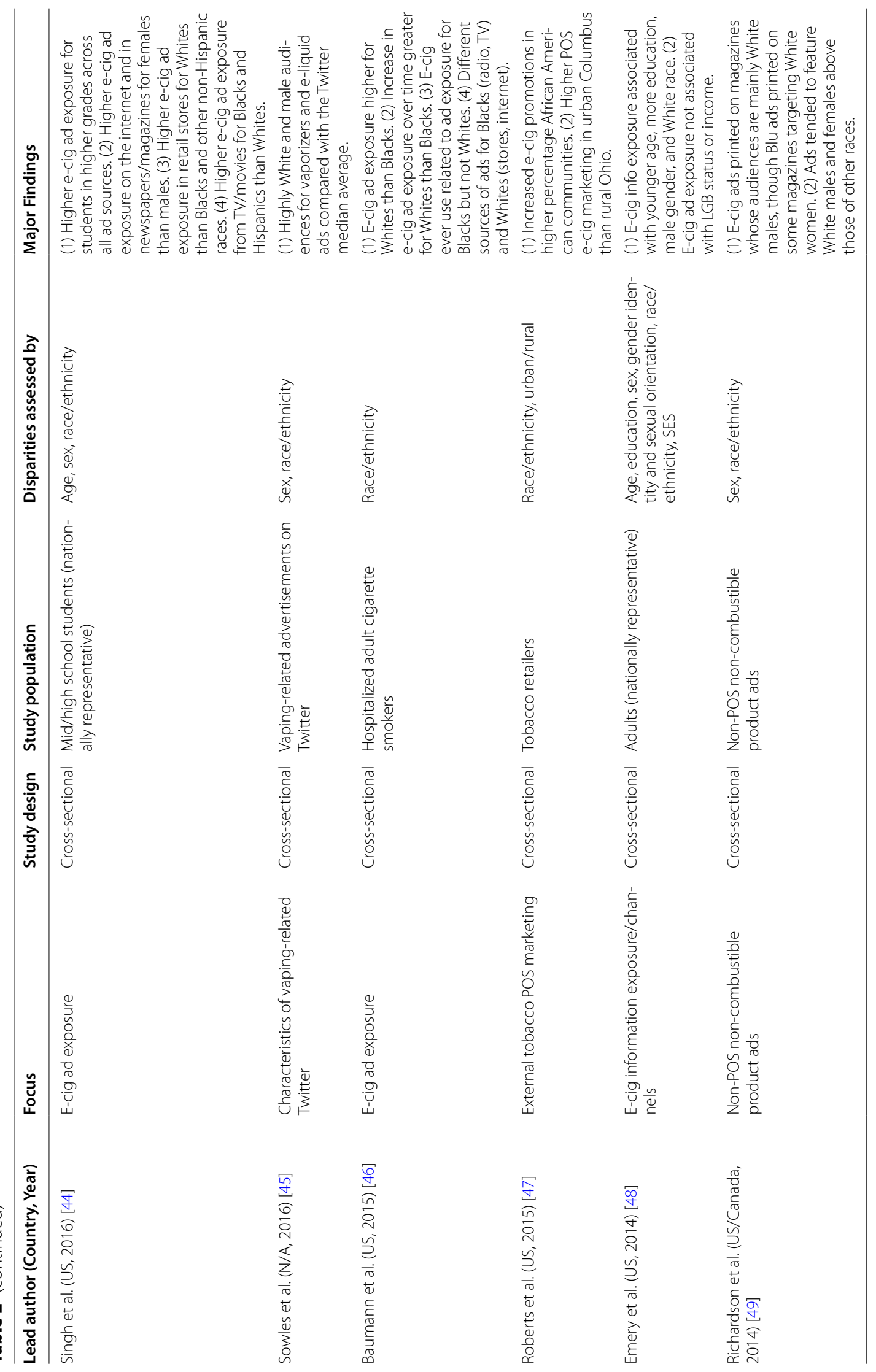


study, of U.S.-middle and high school students, found exposure to e-cigarette advertising through all platforms (POS, Internet, TV/movies, newspapers/magazines) increased as grade level increased [44]. A third nationally representative study of U.S. adults found that the odds of searching for and sharing information about e-cigarettes fell with increasing age, with adults aged 18-24 having the highest odds, followed by adults aged 25-44, 45-64, and then 65 and older [48].

The other studies in the sample observed POS in different areas: contiguous U.S. [36], Guatemala [35], and Nebraska [43]. Two of them, one representative [36] and one non-representative [35], found e-cigarette/ HTP placement near candy and/or sweet beverages, an old tactic used by the tobacco industry to promote cigarettes to children. In Nebraska, the POS with high density of e-cigarette advertising were located in neighborhoods with more young adult and fewer adolescent residents [43].

\section{Education}

Only two studies, both U.S. nationally representative studies, examined exposure to e-cigarette advertising/information by education level; both found advertisement/information exposure to be higher for those with more than a high school diploma. Wagoner et al. found e-cigarette advertisement exposure to be highest for those with some college, followed by those with a 4-yr degree or more and then those with a high school diploma or less [39]. Similarly, Emery et al. also found exposure to e-cigarette information to be associated with more education [48].

\section{Sex}

Only six studies evaluated e-cigarette advertising by sex. Though the exact measurement, population, and advertising source varied by study, results generally found elevated exposure among males compared to females. Three of these studies were nationally representative, two of which found elevated e-cigarette advertisement/ information exposure for male than female adults [39, 48]. The third found e-cigarette advertisement exposure to be higher for female than male middle and high school students on the Internet and in newspapers/magazines [44]. An examination of magazines in the U.S. and Canada found that e-cigarette print ads occurred in magazines whose audiences consisted mainly of White males (e.g. Maxim, Rolling Stone, Men's Journal, and Playboy), but that Blu e-cigarette ads appeared in some magazines targeting White women (e.g. Star and Us Weekly) [49]. On Twitter, the audiences for vaporizers, e-cigarette liquids, and marijuana vape pens were disproportionately male compared to the Twitter median average [45].
Additionally, a non-representative U.S. study found a stronger association between e-cigarette advertisement exposure and use among female than male Californian youth with poor academic performance, conduct problems, and extenuating life circumstances [40].

\section{Gender identity and sexual orientation}

Three nationally representative U.S. studies examined disparities in e-cigarette advertising by LGB status, generally finding elevated e-cigarette advertising exposure among sexual and gender minorities. Of these three studies, only one considered differences between transgender and cisgender individuals as well. One found that LGB status did not predict exposure to e-cigarette information among adults [48]. On the other hand, Emory et al. found that LGBT adults, including both cigarette smokers and non-smokers, were more likely than their nonLGBT counterparts to search for, share, and be exposed to e-cigarette information. They were not, however, more likely to be exposed to anti-tobacco content. Channels of e-cigarette exposure also varied: LGBT individuals were more likely to be exposed to e-cigarettes on the internet and social media, but less likely to be exposed on TV [38]. In a study of young adults, Tan et al. found higher e-cigarette advertisement exposure for bisexual than heterosexual and lesbian women and for gay and heterosexual men than men who identified as 'something else' when controlling for race, ethnicity, education, and tobacco product use; no differences were found in e-cigarette ad exposure between gay or bisexual men and heterosexual men [41].

\section{Race/ethnicity}

Eleven studies reported disparities by race/ethnicity, with four studies also reporting how race/ethnicity intersects with other sociodemographic characteristics. While some studies found that Whites were more likely to be exposed to e-cigarette advertising and information at the individual level (across different populations), other studies found the opposite at the neighborhood level, with non-White areas more likely to have increased advertisement and promotion. Four studies [39, 41, 44, 48] assessing individual exposure were nationally representative and one was not [46]; all five found that Whites were more likely to be exposed to e-cigarette advertising $[39,41,44,46]$ and information [48] than other races. When intersecting race/ethnicity with sexual orientation, Tan et al. found higher exposure to e-cig advertising among heterosexual white women than heterosexual "other races" and bisexual Hispanic than heterosexual non-Hispanic women. Two studies also reported disparities when considering advertisement source of exposure: Singh et al. found that White middle and high school 
students were more likely to be exposed in retailers than Blacks and other non-Hispanic races/ethnicities while Blacks and Hispanics were more likely to be exposed via TV and movies. Similarly, among hospitalized cigarette adult smokers in Alabama, Blacks had greater exposure via radio or television than Whites, whose exposure was higher via stores and the Internet [46]. A study assessing vaping related advertisements on Twitter found that the audience for vaporizers and e-cigarette liquids had a higher proportion of Whites compared to the median Twitter average [45]. Similarly, one study found that e-cigarette print advertisements were more likely to feature White males and females than other races and also to be printed in magazines whose audience was mainly White [49].

Only one study assessing tobacco retailers was nationally representative (in the contiguous U.S. only) [36]. This longitudinal study found higher prevalence of exterior e-cigarette advertising in neighborhoods with a greater proportion of Blacks, and of e-cigarette price promotions among POS located in neighborhoods with a greater proportion of Hispanics. Studies in other areas found similar results: in Nebraska, higher POS e-cigarette advertising density was significantly associated with neighborhoods with a higher proportion of Hispanics [43]; and in Ohio, e-cigarette promotion was found to be higher in neighborhoods with a higher percentage of Black residents [47]. However, a study among low-income, ethnic neighborhoods in Los Angeles found higher availability of e-cigarette advertising in non-Hispanic White neighborhoods compared to Black, Hispanic, Korean-American, and American-Indian neighborhoods [37].

\section{SES}

Five studies examined disparities in e-cigarette advertising/information exposure by SES. The two nationally representative U.S. studies $[36,48]$ found similar results: one found no relationship between self-report income and e-cigarette information exposure [48] and the other found no relationship between neighborhood median household income and e-cigarette promotions or exterior advertising at tobacco retailers that sell cigarettes [36]. There were two non-representative U.S. studies in our sample [42, 43]. Simon et al. found higher advertisement exposure for high than low-SES high schoolers in Connecticut [42]. Wan et al. found higher e-cigarette POS advertising density in areas of Nebraska with lower median family income [43]. One study focused on two large cities in Guatemala. While e-cigarette interior ads were found more frequently at POS in mid-SES neighborhoods, the median numbers of interior ads (for e-cigarettes and HTPs) were higher in high-SES compared to mid-SES neighborhoods [35].

\section{Urban/rural}

Only two studies $[43,47]$ in the sample reported on differences based on urban/rural location. These studies observed tobacco retailers in two different US-states: Nebraska [43] and Ohio [47]. Both found higher e-cigarette advertising or marketing in urban compared to rural areas.

\section{Discussion}

This scoping review found that e-cigarette advertisement presence and exposure differ based on several sociodemographic factors and revealed limited information on HTP advertisement exposure. Although the literature is limited, adolescents and young adults, those with more than a high school diploma, males, sexual and gender minorities, Whites, and urban residents were more likely to be exposed to e-cigarette advertising. Studies focused on the neighborhood-level found e-cigarette advertisements to be more prevalent in non-White neighborhoods. Studies assessing advertising by SES both at the individual and neighborhood level found diverging results, with two reporting more advertising/exposure for higher-SES individuals or neighborhoods, one reporting the opposite for neighborhoods, and two finding no correlation.

It is not surprising that males and Whites were more likely to be exposed to tobacco advertising than their counterparts. Tobacco use has been historically more prevalent among men [50]; moreover, an early study found that print advertisement of e-cigarettes targeted White men [49]. Patterns of e-cigarette use in urban/ rural areas have been mixed [51]. A recent review of the literature also found mixed results in urban/rural areas: while urban neighborhoods were more likely to have tobacco advertising closer to schools, playgrounds, and churches, rural youth were more exposed to tobacco advertising than their urban counterparts [52]. Urban/ rural differences warrant further exploration since only two studies reported on these differences; each one of these studies focused on one U.S. state and might not be generalizable to other states.

Tobacco industry practices of targeting groups that have been excluded or marginalized are well-documented, including among LGBT populations [52-54]. However, only three studies in the sample examined advertising exposure among LGBT adults. Overall tobacco use is higher among LGBT populations than among heterosexuals $[55,56]$; the lack of studies among this population still is a major gap. Future research 
should also consider if/how the tobacco industry's messages and approaches in advertising vary by group and how different messages are received by populations that have been excluded or marginalized; this may improve our understanding of what appeals to different groups, illuminate how the tobacco industry is using this to target populations, and aid in developing more content-appropriate tobacco control mass media campaigns.

Contradictory findings regarding race/ethnicity at the individual versus the neighborhood level warrant further investigation. While evidence suggests that advertising exposure is linked to advertising density among youth [57], this has not been examined by race/ethnicity. In addition, studies that found higher advertisement exposure among Whites collected data between 2012 and 2015 whereas studies that found the opposite collected data between 2014 and 2015, which might indicate a shift in advertising target. A similar pattern has been observed for POS density in the U.S: earlier studies found more e-cigarette retailers in primarily White neighborhoods whereas more recent studies have found increased density in neighborhoods with more racial/ethnic minorities [34]. A more recent study in New York City, however, found a higher prevalence of e-cigarette advertising in higher-income and White neighborhoods whereas lowerincome and predominantly Black and Hispanic neighborhoods had a higher prevalence of other tobacco products, such as cigars and cigarillos [58]. While these findings might not be generalizable, it might indicate that e-cigarette advertising at POS is competing with other tobacco products that have been on the market for a longer time and for which prevalence is higher among Black and Hispanics. Nevertheless, our findings are concerning given the tobacco industry's history of targeting populations that have been excluded or marginalized [9-11].

The majority of the 15 included studies reported on e-cigarette exposure by race/ethnicity (focusing on outcomes among Black, Hispanics, and Whites), followed by age and sex. Moreover, studies in our sample did not assess how sociodemographic characteristics intersect among each other, which might have resulted in different levels of exposure. An intersectional approach might elucidate complex interactions among advertisement exposure across different groups, exposing how different socioeconomic, historical and cultural contexts might be mediating those interactions. In our sample, for example, Tan et al. assessed advertising exposure of different tobacco products considering sexual orientation, sex, and race/ethnicity and found very different patterns of exposure based on intersecting identities and certain tobacco products, essential information when designing interventions.

\section{Strengths and limitations}

Strengths of this study include our search strategy, which was not restricted to a certain timeframe, country, language, population, or study design. However, our selection criteria excluded abstracts that did not specify results on e-cigarette and/or HTPs, which might have resulted in missing relevant studies. In addition, our priority classification of the studies was solely based on our thematic interest and we did not conduct any quality appraisal - a recognized limitation of scoping reviews [33]. Given the significant and rapid changes to the e-cigarette/HTP market, our findings might not be generalizable to today (e.g., many studies in the sample collected data before JUUL's market explosion) [59]. Though we did not limit our search strategy to a specific country, the majority of articles in our sample were U.S.-based; therefore, findings might not be generalizable to other countries. Nevertheless, as e-cigarettes and heated tobacco products become available in other markets, countries can draw on the U.S. experience when considering how to regulate these products. Lessons learned from the U.S. also show the importance of assessing the unintended consequences of certain policies or lack of regulations. In addition, the tobacco industry might exploit policy wins in the U.S. to advocate for the introduction of its products in other countries [60]; given that this is a global industry, information from a specific country might be useful to inform efforts in other countries. Moreover, the use of a framework to classify the literature is a strength of the study, because it informs critical gaps in the literature and highlights needs for the types of future studies to eliminate tobacco-related disparities and support a health equity research agenda.

\section{Implications for research, policy, and practice}

Despite marketing being widely recognized as a driving force of disparities in tobacco use, studies in this review were categorized as second generation according to the HEART paradigm; that is, they sought to determine causal relationships that underlie disparities [15]. However, studies lacked recognition and discussion of factors other than advertising that influence one's health. For example, studies examining e-cigarette or HTP advertising bans should apply an intersectional approach that analyzes these sociodemographic factors within the historical, social, political, cultural, and regulatory context [61] to elucidate the underlying factors that result in health inequities and ways of eliminating them. Overall, studies should be mindful of sample size to have enough statistical power to detect and monitor disparities across groups and subgroups. Further, future research should go beyond evaluating disparities, and address the third and fourth generations of the HEART 
paradigm which aim to evaluate and develop multilevel interventions and take action to achieve health equity. While cross-sectional studies such as those in our sample support the investigation of exposures and outcomes, they do not allow for determining causality and only represent a point in time; mixed-methods research provide a robust methodology to support the assessment of multilevel interventions [15]. To foster this critical research to be undertaken, research funding streams should encourage and prioritize health equity research, including community based participatory research, and increase involvement and leadership from researchers of diverse backgrounds. Moreover, it is fundamental that researchers work in partnerships with governments and local communities on eliminating health inequities.

The potential benefits of e-cigarettes as a cessation aid and heated tobacco products as a less toxic product compared to cigarettes are yet to be confirmed. Still, these are harmful products, especially for those who have not previously initiated any tobacco use, and their regulation has presented challenges to governments around the world. Therefore, it is essential to implement strong restrictions to tobacco advertising and promotion in order to avoid unintended consequences such as youth uptake $[62,63]$. It is also important to consider the impact of any proposed policy on the basis of the multiple factors discussed here to avoid increasing or maintaining tobaccorelated disparities even if tobacco use is reduced overall.

\section{Conclusions}

This study showed that e-cigarette and HTP advertising and promotion varies based on several sociodemographic characteristics; given that the potential benefits of these products would be restricted to current smokers and youth were more likely to be exposed to advertising, tobacco-related disparities might further increase. Moreover, this study highlights the need for research explicitly incorporating and applying a health equity lens from its inception in order to obtain data that can support the elimination of tobacco-related disparities.

\section{Abbreviations \\ HEART: Health Equity Action Research Trajectory; HTP: Heated tobacco prod- uct; POS: Point-of-sale; SES: Socioeconomic status.}

\section{Acknowledgements}

We would like to thank Ayodeji J. Awopegba for his contributions during the coding process. We also would like to thank the experts who participated in the consultation meeting, contributed to a lively discussion and provided valuable feedback to this project.

\section{Authors' contributions}

GG conducted the bibliographical search. GG and EC conducted data collection, coding, analysis and interpretation of data. GG and EC wrote the first draft of the manuscript. JEC contributed to the design of the study, resolved disagreements between coders, and critically reviewed manuscript drafts. All authors read and approved the final manuscript.

\section{Funding}

Support for this research was provided by the Robert Wood Johnson Foundation. The views expressed here do not necessarily reflect the views of the Foundation.

Availability of data and materials

All data analyzed during this study are included in this published article.

\section{Declarations}

Ethics approval and consent to participate

This study did not require ethical approval.

Consent for publication

Not applicable.

\section{Competing interests}

The authors do not have any competing interests.

Received: 10 May 2021 Accepted: 19 October 2021

Published online: 30 October 2021

\section{References}

1. Marmot M, Friel S, Bell R, Houweling TA, Taylor S. Closing the gap in a generation: health equity through action on the social determinants of health. Lancet. 2008;372(9650):1661-9.

2. Braveman P, Egerter S, Williams DR. The social determinants of health: coming of age. Annu Rev Public Health. 2011;32(1):381-98.

3. McGovern L. Health policy brief: the relative contribution of multiple determinants to health outcomes. Health Aff (Millwood). 2014; https:// www.healthaffairs.org/do/10.1377/hpb20140821.404487/full/. Accessed 26 Mar 2021.

4. Marbin J, Balk SJ, Gribben V, Groner J. Health disparities in tobacco use and exposure: a structural competency approach. Pediatrics. 2021:147(1):e2020040253.

5. Cigarette and tobacco use among people of low socioeconomic status. Centers for Disease Control and Prevention. 2019. https://www.cdc.gov/ tobacco/disparities/low-ses/index.htm. Accessed 15 Mar 2021.

6. Garrett BE. Socioeconomic differences in cigarette smoking among sociodemographic groups. Prev Chronic Dis. 2019;16(E74):1-6.

7. Lewer D, McKee M, Gasparrini A, Reeves A, de Oliveira C. Socioeconomic position and mortality risk of smoking: evidence from the English longitudinal study of ageing (ELSA). Eur J Pub Health. 2017;27(6):1068-73.

8. Jha P, Peto R, Zatonski W, Boreham J, Jarvis MJ, Lopez AD. Social inequalities in male mortality, and in male mortality from smoking: indirect estimation from national death rates in England and Wales, Poland, and North America. Lancet. 2006;368(9533):367-70.

9. Lee JGL, Henriksen L, Rose SW, Moreland-Russell S, RibisI KM. A systematic review of neighborhood disparities in point-of-sale tobacco marketing. Am J Public Health. 2015;105(9):e8-18.

10. Laws MB, Whitman J, Bowser DM, Krech L. Tobacco availability and point of sale marketing in demographically contrasting districts of Massachusetts. Tob Control. 2002;11 Suppl 2:ii71-3.

11. Davis RM, Gilpin E, Loken B, Viswanath $K$, Wakefield M. The role of the media in promoting and reducing tobacco use. Tobacco control monograph no. 19. Bethesda, MD: National Cancer Institute; 2008. http://doi. apa.org/get-pe-doi.cfm?doi=10.1037/e481902008-001. Accessed 16 Mar 2021

12. Lynch BS, Bonnie RJ. Social norms and the acceptability of tobacco use. Growing up Tobacco Free: Preventing Nicotine Addiction in Children and 
Youths. National Academies Press; 1994. https://www.ncbi.nlm.nih.gov/ books/NBK236769/. Accessed 5 Feb 2021.

13. National Center for Chronic Disease Prevention and Health Promotion (US) Office on Smoking and Health. The tobacco industry's influences on the use of tobacco among youth. In: Preventing Tobacco Use Among Youth and Young Adults: A Report of the Surgeon General. Centers for Disease Control and Prevention (US); 2012. https://www.ncbi.nlm.nih. gov/books/NBK99238/. Accessed 5 Feb 2021.

14. Braveman PA, Arkin E, Orleans T, Proctor D, Plough A. What is health equity? And what difference does a definition make? Princeton, $\mathrm{NJ}$ : Robert Wood Johnson Foundation; 2017. https://www.rwjf.org/en/libra ry/research/2017/05/what-is-health-equity-html. Accessed 5 Oct 2020.

15. Thomas SB, Quinn SC, Butler J, Fryer CS, Garza MA. Toward a fourth generation of disparities research to achieve health equity. Annu Rev Public Health. 2011;32(1):399-416.

16. Bialous SA, Glantz SA. Heated tobacco products: another tobacco industry global strategy to slow progress in tobacco control. Tob Control. 2018;27(Suppl 1):s111-7.

17. Choi K, Grana R, Bernat D. Electronic nicotine delivery systems and acceptability of adult cigarette smoking among Florida youth: renormalization of smoking? J Adolesc Health. 2017;60(5):592-8.

18. Collins L, Glasser AM, Abudayyeh H, Pearson JL, Villanti AC. E-cigarette marketing and communication: how e-cigarette companies market e-cigarettes and the public engages with e-cigarette information. Nicotine Tob Res. 2019;21(1):14-24.

19. Grabovac I, Oberndorfer M, Fischer J, Wiesinger W, Haider S, Dorner TE. Effectiveness of electronic cigarettes in smoking cessation: a systematic review and Meta-analysis. Nicotine Tob Res. 2021;23(4):625-34.

20. Bozier J, Chivers EK, Chapman DG, Larcombe AN, Bastian NA, Masso-Silva $\mathrm{JA}$, et al. The evolving landscape of e-cigarettes: a systematic review of recent evidence. Chest. 2020;157(5):1362-90

21. Simonavicius E, McNeill A, Shahab L, Brose LS. Heat-not-burn tobacco products: a systematic literature review. Tob Control. 2019;28(5):582-94.

22. Dunbar MS, Seelam R, Tucker JS, Rodriguez A, Shih RA, D'Amico EJ. Correlates of awareness and use of heated tobacco products in a sample of US young adults in 2018-2019. Nicotine Tob Res. 2020;22(12):2178-87.

23. Fried ND, Gardner JD. Heat-not-burn tobacco products: an emerging threat to cardiovascular health. Am J Physiol-Heart Circ Physiol. 2020;319(6):H1234-9.

24. Mallock N, Pieper E, Hutzler C, Henkler-Stephani F, Luch A. Heated tobacco products: a review of current knowledge and initial assessments. Front Public Health. 2019; https://www.ncbi.nlm.nih.gov/pmc/articles/ PMC6795920/.

25. Ali FRM, Marynak KL, Kim Y, Binns S, Emery SL, Gomez Y, et al. E-cigarette advertising expenditures in the USA, 2014-2018. Tob Control. 2020;29(e1):e124-6.

26. Surgeon General. Surgeon General's advisory on e-cigarette use among youth. https://e-cigarettes.surgeongeneral.gov/documents/surgeongenerals-advisory-on-e-cigarette-use-among-youth-2018.pdf. Accessed 29 Sep 2021.

27. Hawkins KB, Johnson AC, Denzel M, Tercyak KP, Mays D. Adolescents' awareness and perceptions of e-cigarettes: Implications for intervention and tobacco regulation. Pediatrics. 2017:140(1 MeetingAbstract):132.

28. Padon AA, Maloney EK, Cappella JN. Youth-targeted e-cigarette marketing in the US. Tob Regul Sci. 2017;3(1):95-101.

29. Zhang Y, Bu F, Dong F, Wang J, Zhu S-J, Zhang X, et al. The effect of e-cigarettes on smoking cessation and cigarette smoking initiation: an evidence-based rapid review and meta-analysis. Tob Induc Dis. 2021;19:04

30. Hartwell G, Thomas S, Egan M, Gilmore A, Petticrew M. E-cigarettes and equity: a systematic review of differences in awareness and use between sociodemographic groups. Tob Control. 2017;26:e85-91.

31. Lucherini M, Hill S, Smith K. Potential for non-combustible nicotine products to reduce socioeconomic inequalities in smoking: a systematic review and synthesis of best available evidence. BMC Public Health. 2019;19(1):1469.

32. Lucherini M, Hill S, Smith K. Inequalities, harm reduction and non-combustible nicotine products: a meta-ethnography of qualitative evidence. BMC Public Health. 2020;20(1):943.

33. Arksey H, O'Malley L. Scoping studies: towards a methodological framework. Int J Soc Res Methodol. 2005:8(1):19-32.
34. Striving towards equity: A scoping review of e-cigarettes, HTPs, and tobacco-related disparities. Institute for Global Tobacco Control; 2020 https://www.globaltobaccocontrol.org/striving_towards_equity. Accessed 29 Mar 2021.

35. Barnoya J, Monzon D, Pinetta J, Grilo G, Cohen JE. New tobacco products, old advertising strategies: point-of-sale advertising in Guatemala. Tob Control. 2020; https://tobaccocontrol.bmj.com/content/early/ 2020/08/19/tobaccocontrol-2020-055681.

36. D'Angelo H, Rose SW, Golden SD, Queen T, Ribisl KM. E-cigarette availability, price promotions and marketing at the point-of sale in the contiguous United States (2014-2015): national estimates and multilevel correlates. Prev Med Rep. 2020;19:101152.

37. Escobedo P, Garcia R, Soto C, Rodriguez Y, Barahona R, BaezcondeGarbanati L. Comparison of e-cigarette marketing and availability in tobacco retail outlets among diverse low-income communities in California. Tob Control. 2020;29(4):469-71.

38. Emory K, Buchting FO, Trinidad DR, Vera L, Emery SL. Lesbian, gay, bisexual, and transgender (LGBT) view it differently than non-LGBT: exposure to tobacco-related couponing, e-cigarette advertisements, and anti-tobacco messages on social and traditional media. Nicotine Tob Res. 2019;21(4):513-22.

39. Wagoner KG, Reboussin DM, King JL, Orlan E, Ross JC, Sutfin EL. Who is exposed to e-cigarette advertising and where? Differences between adolescents, young adults and older adults. Int J Environ Res Public Health. 2019;16(14):2533

40. Pike JR, Tan N, Miller S, Cappelli C, Xie B, Stacy AW. The effect of e-cigarette commercials on youth smoking: a prospective study. Am J Health Behav. 2019;43(6):1103-18.

41. Tan ASL, Hanby EP, Sanders-Jackson A, Lee S, Viswanath K, Potter J. Inequities in tobacco advertising exposure among young adult sexual, racial and ethnic minorities: examining intersectionality of sexual orientation with race and ethnicity. Tob Control. 2021;30(1):84-93.

42. Simon P, Camenga DR, Morean ME, Kong G, Bold KW, Cavallo DA, et al. Socioeconomic status and adolescent e-cigarette use: the mediating role of e-cigarette advertisement exposure. Prev Med. 2018;112:193-8.

43. Wan N, Siahpush M, Shaikh RA, McCarthy M, Ramos A, Correa A. The association of point-of-sale e-cigarette advertising with socio-demographic characteristics of neighborhoods. J Prim Prev. 2018;39(3):191-203.

44. Singh T, Marynak K, Arrazola RA, Cox S, Rolle IV, King BA. Vital signs: exposure to electronic cigarette advertising among middle school and high school students - United States, 2014. MMWR. 2016;64(52):1403-8.

45. Sowles SJ, Krauss MJ, Connolly S, Cavazos-Rehg P. A content analysis of vaping advertisements on twitter. Prev Chronic Dis. 2016;13(9):E139.

46. Baumann AW, Kohler C, Kim Yl, Cheong J, Hendricks P, Bailey WC, et al. Differences in electronic cigarette awareness, use history, and advertisement exposure between black and White hospitalized cigarette smokers. J Cancer Educ. 2015;30(4):648-54.

47. Roberts ME, Berman ML, Slater MD, Hinton A, Ferketich AK. Point-of-sale tobacco marketing in rural and urban Ohio: could the new landscape of tobacco products widen inequalities? Prev Med. 2015;81:232-5.

48. Emery SL, Vera L, Huang J, Szczypka G. Wanna know about vaping? Patterns of message exposure, seeking and sharing information about e-cigarettes across media platforms. Tob Control. 2014:23 Suppl 3:iii17-25.

49. Richardson A, Ganz O, Stalgaitis C, Abrams D, Vallone D. Noncombustible tobacco product advertising: how companies are selling the new face of tobacco. Nicotine Tob Res. 2014;16(5):606-14.

50. Higgins ST, Kurti AN, Redner R, White TJ, Gaalema DE, Roberts ME, et al. A literature review on prevalence of gender differences and intersections with other vulnerabilities to tobacco use in the United States, 2004-2014. Prev Med. 2015;80:89-100.

51. Talbot JA, Williamson ME, Pearson $K$, Lenardson J, Ziller E, Jimenez F, et al. Advancing tobacco prevention and control in rural America. Washington, DC: National Network of Public Health Institutes; 2019. https://nnphi.org/ wp-content/uploads/2019/02/AdvancingTobaccoPreventionControlRu ralAmerica.pdf. Accessed 29 Mar 2021

52. CruzTB, Rose SW, Lienemann BA, Byron MJ, Meissner HI, BaezcondeGarbanati L, et al. Pro-tobacco marketing and anti-tobacco campaigns aimed at vulnerable populations: a review of the literature. Tob Induc Dis. 2019;17:68. 
53. Apollonio DE, Malone RE. Marketing to the marginalised: tobacco industry targeting of the homeless and mentally ill. Tob Control. 2005;14(6):409-15.

54. Dilley J, Boysun M, Dent C, Pizacani B. Does tobacco industry marketing excessively impact lesbian, gay and bisexual communities? Tob Control. 2008;17(6):385-90.

55. Drope J, Liber AC, Cahn Z, Stoklosa M, Kennedy R, Douglas CE, et al. Who's still smoking? Disparities in adult cigarette smoking prevalence in the United States. CA Cancer J Clin. 2018:68(2):106-15.

56. Lesbian G. Bisexual, and transgender persons and tobacco use. Centers for Disease Control and Prevention. 2020; https://www.cdc.gov/tobacco/ disparities/lgbt/index.htm. Accessed 2 Apr 2021.

57. Loomis BR, Kim AE, Busey AH, Farrelly MC, Willett JG, Juster HR. The density of tobacco retailers and its association with attitudes toward smoking, exposure to point-of-sale tobacco advertising, cigarette purchasing, and smoking among New York youth. Prev Med. 2012;55(5):468-74.

58. Giovenco DP, Spillane TE, Merizier JM. Neighborhood differences in alternative tobacco product availability and advertising in new York City: implications for health disparities. Nicotine Tob Res. 2019;21(7):896-902.

59. Huang J, Duan Z, Kwok J, Binns S, Vera LE, Kim Y, et al. Vaping versus JUULing: how the extraordinary growth and marketing of JUUL transformed the US retail e-cigarette market. Tob Control. 2019;28(2):146-51.
60. PMI promotion of IQOS using FDA MRTP order. Tobacco Tactics. 2021 https://tobaccotactics.org/wiki/pmi-iqos-fda-mrtp-order/. Accessed 29 Sep 2021.

61. Potter LN, Lam CY, Cinciripini PM, Wetter DW. Intersectionality and smoking cessation: exploring various approaches for understanding health inequities. Nicotine Tob Res. 2020;23(1):115-23.

62. Health Canada confirms ban of advertising for vaping products wherever they can be seen or heard by youth. Government of Canada. 2020. https://www.canada.ca/en/health-canada/news/2020/07/health-canadaconfirms-ban-of-advertising-for-vaping-products-wherever-they-can-beseen-or-heard-by-youth.html. Accessed 1 Apr 2021.

63. Hammond D, Reid JL, Burkhalter R, Rynard VL. E-cigarette marketing regulations and youth vaping: cross-sectional surveys. Pediatrics. 2020;146(1):e20194020.

\section{Publisher's Note}

Springer Nature remains neutral with regard to jurisdictional claims in published maps and institutional affiliations.
Ready to submit your research? Choose BMC and benefit from:

- fast, convenient online submission

- thorough peer review by experienced researchers in your field

- rapid publication on acceptance

- support for research data, including large and complex data types

- gold Open Access which fosters wider collaboration and increased citations

- maximum visibility for your research: over $100 \mathrm{M}$ website views per year

At BMC, research is always in progress.

Learn more biomedcentral.com/submissions 